American Journal of Immunology 3 (2): 35-44, 2008

ISSN 1553-619X

(C) 2008 Science Publications

\title{
Evaluation of the Immunomodulatory Properties of a Calf Lipid Thymus Extract and Standardization of a Method for Quantification of its Biological Activity
}

\author{
${ }^{1}$ Miodrag Colic, ${ }^{2}$ Radmila Popovic, ${ }^{2}$ Dusanka Mrdakovic, ${ }^{2}$ Milena Radeta, \\ ${ }^{2}$ Jasna Novakovic, ${ }^{2}$ Bojan Pavlovic and ${ }^{1}$ Dragana Vucevic \\ ${ }^{1}$ Institute for Medical Research, Military Medical Academy, \\ Crnotravska 17, 11002 Belgrade, Serbia \\ ${ }^{2}$ Galenika A.D., Research and Development Institute, \\ Batajnicki drum BB, 11080 Belgrade, Serbia
}

\begin{abstract}
The aim of this study was to test the immunobiological properties of a new formulation of the lipid thymus calf extract (Thymsol), prepared for in vitro cell culture experiments. At first, we showed that Thymsol enhanced the antigen specific immune response in $\mathrm{AO}$ rats in vivo, using Keyhole limpet hemocyanin (KLH). At lower concentrations $\left(0.5-2.5 \mu \mathrm{g} \mathrm{mL}^{-1}\right)$ the extract increased the proliferation of rat spleen lymphocytes in vitro, stimulated with suboptimal concentrations of Concanavalin A (ConA) or anti-T-cell receptor (TCR) monoclonal antibody (mAb), followed by an increase in the production of interleukin-2 (IL-2). Stimulation of IL-2 production was additionally enhanced in the presence of a blocking anti-IL-2 receptor $\alpha \mathrm{mAb}$. Higher concentrations of Thymsol (20-60 $\left.\mathrm{g} \mathrm{mL}^{-1}\right)$ showed a dose-dependent inhibition of lymphocyte proliferation. After testing the variability in IL-2 production by anti-TCR mAb-activated splenocytes, using several stimulatory concentrations of different Thymsol samples, and the production of this cytokine by different cultures of splenocytes treated with the same Thymsol sample, we proposed an IL-2-based method for quantification of the immunobiological activity of the extract.
\end{abstract}

Key words: Thymus extract, immune response, proliferation, IL-2 production

\section{INDTRODUCTION}

The thymus gland plays a crucial role in the development and maintenance of immunity and tolerance, as it provides the microenvironment for $\mathrm{T}$ cell differentiation, maturation and selection ${ }^{[1]}$. The intrathymic development of $\mathrm{T}$ cells results from cell-tocell interactions between $\mathrm{T}$-cell precursors and microenvironmental cells and the activity of soluble factors. Among them, thymic hormones play the most important role and act not only on thymic $\mathrm{T}$ cells but also on peripheral mature $\mathrm{T}$ cells $\mathrm{s}^{[1,2]}$. It is postulated that the involution of the thymus gland and subsequent decline of thymic hormone secretion are involved, to a considerable extent, in the development of the ageassociated immune deficiency ${ }^{[3,4]}$. In this regard substitutive therapy with thymic hormones or different thymic extracts was reported to improve or restore ageassociated immune defects in both experimental animals and humans ${ }^{[5-7]}$. Later on, the therapeutic application of thymic preparation has been extented to different fields in clinical medicine such as acute and chronic infectious diseases, chronic allergies, cancer, autoimmune diseases, complication of sepsis, immunosuppresion after chemotherapy and radiotherapy and many others ${ }^{[8,9]}$.

Significant therapeutic value of thymus extracts, published up to now in large number of papers, is predominantly related to the improvement of cellular immune functions, especially those of $\mathrm{T}$ cells. Thymus extracts have been shown to modulate the development, maturation and activation of $\mathrm{T}$ cells ${ }^{[8-11]}$, enxance their responsivenes to mitogens ${ }^{[12-14]}$, stimulate production of interleukin-2 (IL-2) ${ }^{[12-16]}$ and T helper 1 (Th1) immune responses ${ }^{[17]}$.

Many commercial preparations of liquid thymus extracts typically contain thymic hormones, but also many other water soluble peptides and components, which contribute additionally to their biological effects. Therefore, for companies and laboratories producing thymus extracts to be used for therapeutic or research procedures, it is very important to establish relevant

Corresponding Author: Miodrag Colic, Institute for Medical Research, Military Medical Academy, Crnotravska 17, 11002 Belgrade, Serbia, Tel/Fax: +381-11-2662-722 
screening tests for quantification of the biological activity of different butches of such preparations.

Several years ago, we started with the research of a new calf thymus extract, predominantly composed of lipids, to be potentially used for clinical application in human and veterinary medicine. A number of results, collected up to now from preclinical studies showed that this calf thymus lipid extract (CTLE) possesses immunomodulatory activity ${ }^{[18]}$ (and Vucevic et al., manuscript submitted) and improves wound healing (data not shown). Since there were difficulties in mixing the lipid extract with cell culture medium for evaluation of its immunobiological activity, we prepared a new formulation of CTLE suitable for in vitro experiments. The aim of this work was to check the effect of this extract on the immune response in vivo and in vitro and to standardize a method for quantification of its biological activity.

\section{MATERIALS AND METHODS}

Animals: Experiments were performed on Albino Oxford (AO) rats, male, 6 months old, bread at the vivarium of the Institute of Medical Research, Military Medical Academy, Belgrade, under conventional laboratory conditions.

Preparation of Thymsol: The calf thymus gland was obtained from a slaughter-house. After removal, the gland was immediately frozen at $-20^{\circ} \mathrm{C}$ and transported to the laboratory. The frozen thymus was milled and than suspended in a polar organic solvent (n-butyl alcohol). Extraction was done by using an azeotropic distillation process. The ballast material was drained and the total extract was concentrated and vacuum dried. The non-lipid component was removed from the dried total extract, using a Folch method ${ }^{[19]}$ and rest of the fraction (lipid extract), containing 97.0-97.7\% lipids and about $0.3 \%$ peptides, was further processed as we previously described ${ }^{[18]}$. The CTLE was solubilized and emulsified in benzyl alcohol, butylated hydroxyanisole, ethyl oleate, benzyl benzoate, Cremophor EL and water for injections. The components of the solvent were obtained from Merck, whereas Cremophor EL was from BASF, Ludwigshagen, Germany. The concentrations of all used excipients were permited for parenteral administration according to the European Pharmacopea V. After sterlization by filtration, the preparation, named Thymsol, was ampulated at the concentration of $50 \mu \mathrm{g} \mathrm{mL} L^{-1}$. The placebo ampules contained the solvent/emulgator components without CTLE.
Immunization protocol: Rats were immunized by injection of Keyhole limpet hemocyanin (KLH) (Sigma, Munich, Germany) $\left(2 \mathrm{mg} \mathrm{mL}^{-1}\right)$ emulsified in the complete Freund's adjuvant (CFA) (Sigma) in a total volume of $100 \mu \mathrm{L}$ into right posterior footpads. The experimental group was injected with $2.5 \mathrm{mg} 100^{-1}$ $\mu \mathrm{L}$ of Thymsol into the same footpad, one hour before immunization. The same procedure was repeated after 4 days of immunization. Two control groups were used. The placebo group was treated with the same volume of placebo before and after immunization. The pure control group was treated with the same volume of saline. After 10 days draining popliteal lymph nodes were removed and cells were prepared.

Preparation of lymph node lymphocytes and splenocytes: Lymph node lymphocytes from immunized animals were aseptically removed, pressed through stainless meshes placed in Petri dishes with addition of phosphate buffered saline (PBS) $+5 \%$ fetal calf serum (FCS) (ICN, Costa Mesa, CA), filtered through nylon gauze to remove large debris and clumps and then washed twice by centrifugation $(580 \mathrm{xg})$ with RPMI medium (Sigma)+5\% FCS. Cells were counted and their viability (usually higher than 95\%) was determined by trypan blue dye exclusion.

Splenocytes were isolated from intact AO rats using the same procedure as described for lymph node lymphocytes. Red blood cells from splenocyte suspensions were lysed using a hypotonic amonium chloride buffer, following by two subsequent cell washings $(120 \mathrm{xg})$ with RPMI medium+5\% FCS. Viability of the cells was between $93-96 \%$.

Proliferation assays: Lymph node lymphocytes were resuspended in complete RPMI medium (RPMI medium+10\% FCS+2 mM L-glutamine+10 $\mathrm{U} \mathrm{mL}^{-1}$ penicillin+1 $\mathrm{mg} \mathrm{mL}^{-1}$ streptomycin) and adjusted to a concentration of $2.0 \times 10^{6}$ cells $\mathrm{mL}^{-1}$. Cells were cultivated for $96 \mathrm{~h}$ in 96-well plates (ICN) $(200 \mu \mathrm{L}$ well ${ }^{-1}$ ) in an incubator with $5 \% \mathrm{CO}_{2}$ at $37^{\circ} \mathrm{C}$ with different concentrations of KLH. Splenocytes $\left(2.0 \times 10^{6}\right.$ cells $\mathrm{mL}^{-1}, 200 \mu \mathrm{L}$ well ${ }^{-1}$ ) were incubated in culture medium alone, different concentrations of Thymsol or corresponding concentrations of placebo for $72 \mathrm{~h}$ as described for lymph node cells. Proliferation of splenocytes was induced with a suboptimal concentration $\left(1.25 \mu \mathrm{g} \mathrm{mL}^{-1}\right)$ of ConcanavalinA (ConA) (Sigma) or a suboptimal concentration $\left(0.1 \mu \mathrm{g} \mathrm{mL}^{-1}\right)$ of an anti-T cell receptor (TCR) monoclonal antibody (mAb) (R73) (Serotec, Oxford, UK). During the last 18 $\mathrm{h}$ of cultivation, cells were pulsed with $1 \mu \mathrm{Ci}$ well ${ }^{-1}$ 
$\left.{ }^{3} \mathrm{H}\right]$ thymidine $\left(6,7 \mathrm{Ci} \mathrm{mmol}^{-1}\right.$, Amersham, Books, U.K.). After harvesting, the radioactivity was counted using a scintillation counter (Beckman). Results were expressed as mean counts per minute (cpm) of triplicates.

Production of interleukin-2 (IL-2): Lymph node lymphocytes from immunized animals were cultivated with $\mathrm{KLH}\left(50 \mu \mathrm{L} \mathrm{mL}^{-1}\right)$ for $48 \mathrm{~h}$ as described for the proliferation assay. Splenocytes, stimulated with R73 $\mathrm{mAb}$ with or without a blocking IL-2R $\alpha \mathrm{mAb}$ (OX-39) (Serotec, Oxford, UK) at the concentration of $10 \mu \mathrm{g}$ $\mathrm{mL}^{-1}$, were treated with Thymsol or placebo and cultivated for $48 \mathrm{~h}$. Cell-free supernatants were assayed for the presence of IL-2 using a commercial rat IL-2 ELISA kit ( $\mathrm{R}$ and $\mathrm{D})$, following exactly the instructions of the manufacturer. Results are expressed as $\mathrm{pg} \mathrm{mL}^{-1}$ of triplicates.

Statistic analysis: The data are presented as a mean \pm SD. Student's t-test was used for statistical analysis of the results. The values $(\mathrm{p}<0.05)$ or less were considered to be statistically significant. Coefficient of variation $(\mathrm{CV})$ was calculated as follows: $\mathrm{CV}(\%)=$ standard deviation $(\mathrm{SD}) /$ mean value $\times 100$.

\section{RESULTS AND DISCUSSION}

Effect of Thymsol on the antigen-specific immune response in vivo: The first aim of this study was to test whether a new formulation of CTLE (Thymsol), exerts the immunomodulatory activity in vivo. For this purpose we immunized rats with KLH, with or without Thymsol, as described in Materials and methods. A control group of rats was treated similarly with the same volume of placebo.

As shown in Fig 1A, the treatment of animals with Thymsol resulted in significantly higher cellularity of regional lymph nodes, compared with both control groups. Lymph node cells, isolated from immunized animals, showed a dose-dependent proliferation in vitro in the presence of KLH (Fig 1B). Although cellular proliferation in cultures from the placebo group was a bit higher compared to the pure control group (rats immunized with KLH, only), the proliferative response of lymphocytes from the experimental group was statistically significantly higher compared to both control groups and these results correlated with higher production of IL-2 (Fig 1C).

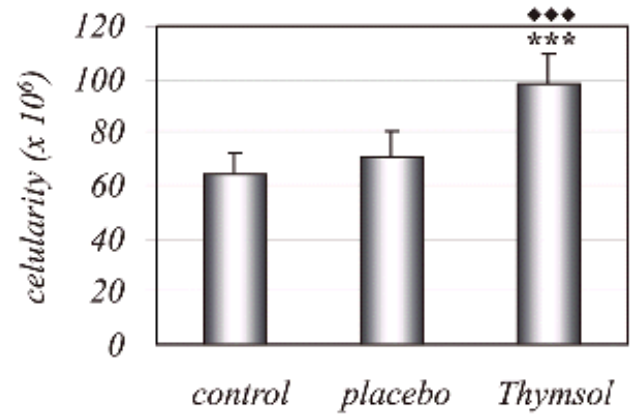

(A)

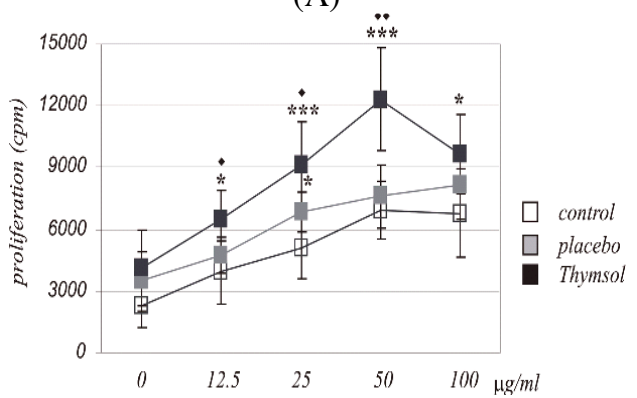

(B)

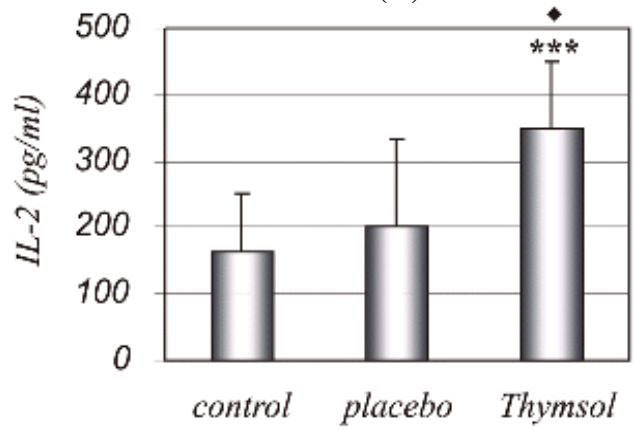

(C)

Fig. 1: Effect of Thymsol on cellularity of lymph nodes (A), proliferation (B) and production of IL-2 (C) by lymph node lymphocytes isolated from rats immunized with KLH Rats ( $n=6$ /group) were immunized by KLH as described in Materials and methods. After 10 days draining popliteal lymph nodes were removed and cells were prepared. Proliferation was measured by a $\left[{ }^{3} \mathrm{H}\right]-$ thymidine method, after stimulation of lymph node lymphocytes with different concentrations of KLH. The levels of IL-2 in culture supernatants (24h after cultivation) were determined by ELISA, as described in Material and methods. $*=\mathrm{p}<0.05, * * *=\mathrm{p}<0.005$ compared to corresponding controls, $\bullet=\mathrm{p}<0.05$, $\bullet=\mathrm{p}<0.01, \bullet \bullet=\mathrm{p}<0.005$ compared to corresponding values of placebo 
Am. J. Immunol., 3 (2): 35-44, 2008

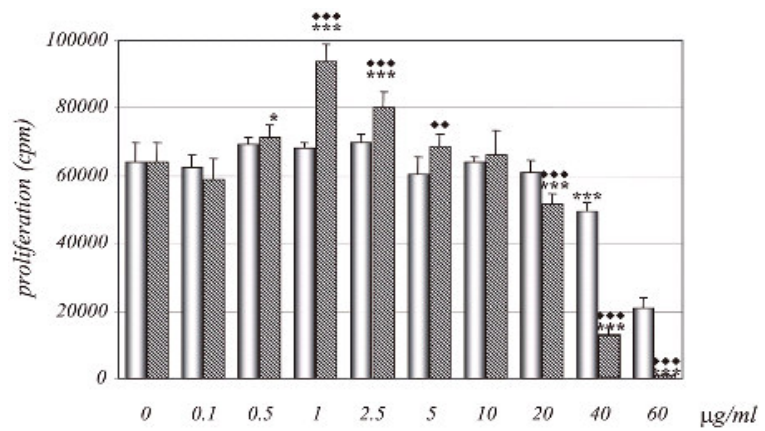

(A)

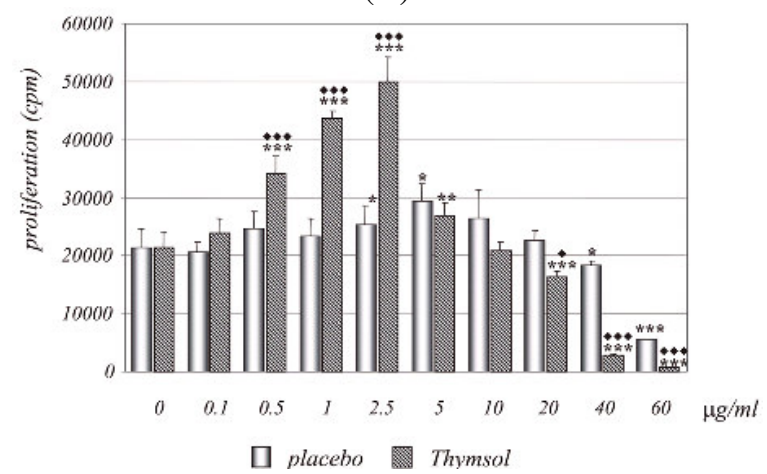

(B)

Fig. 2: Effect of different concentrations of Thymsol or placebo on the proliferation of rat splenocytes in cultures stimulated with ConA (A) or R73 mAb (B) Splenocytes were stimulated with ConA $\left(1.25 \mu \mathrm{g} \mathrm{mL}^{-1}\right)$ or $\mathrm{R} 73\left(0.1 \mu \mathrm{g} \mathrm{mL}^{-1}\right)$ for 3 days. The cultures were treated with different concentrations of Thymsol or placebo. Cellular proliferation was measured by a $\left[{ }^{3} \mathrm{H}\right]$-thymidine method as described in Materials and methods. Values are given as mean $\mathrm{cpm} \pm \mathrm{SD}$ of triplicates of one representative experiment (of 4 with similar results). $=\mathrm{p}<0.05 ; * *=\mathrm{p}<0.01 ; * * *=$ $\mathrm{p}<0.005$ compared to corresponding cultures without Thymsol or placebo, $\bullet=\mathrm{p}<0.05 ; \bullet \bullet=$ $\mathrm{p}<0.01, \quad \bullet \bullet=\mathrm{p}<0.005$ compared to corresponding placebo cultures

Effect of different concentrations of Thymsol on the proliferation of rat splenocytes in vitro: Based on the previous results we examined the effect of different concentrations of Thymsol and placebo on the proliferation of rat splenocytes in vitro. For stimulation of the cells, two T-cell mitogens were used: a suboptimal concentration of ConA $\left(1.25 \mu \mathrm{g} \mathrm{mL}^{-1}\right)$ and a suboptimal concentration of R73 (anti-TCR) mAb. Fig $2 \mathrm{~A}$ shows that Thymsol at concentrations between 0.5 and $5.0 \mu \mathrm{g} \mathrm{mL}^{-1}$ augmented the proliferation of ConAstimulated splenocytes, whereas the concentrations between 20-60 $\mu \mathrm{g} \mathrm{mL}^{-1}$ showed a dose-dependent inhibition of cellular proliferation. The proliferation of splenocytes triggered by R73 mAb was lower compared to ConA, but the stimulatory effect of Thymsol was significantly higher. Similarly, higher doses of Thymsol were inhibitory in this assay (Fig 2B).

The stimulatory activity of Thymsol, compared to placebo, was confirmed in four independent experiments. However, the maximum stimulation varied between the experiments and the results can be summarized as follows. The lowest stimulation: 1.2 fold increase at $2.5 \mu \mathrm{g} \mathrm{mL}^{-1}$ of Thymsol (ConA), 1.7 fold increase at $1.0 \mu \mathrm{g} \mathrm{mL}^{-1}$ of Thymsol (R73 mAb), the highest stimulation: 2.1 fold increase at $1.0 \mu \mathrm{g} \mathrm{mL}^{-1}$ of the extract (ConA), 3.4 fold increase at $2.5 \mu \mathrm{g} \mathrm{mL}^{-1}$ of the extract (R73 mAb).

Stimulatory and inhibitory activity of placebo was also evident at certain lower or higher concentrations, respectively, in both assays, but its effect was less pronounced compared to the corresponding concentrations of Thymsol (Fig 2A and Fig 2B).

Production of IL-2 in vitro by R73-stimulated splenocytes: Previous results clearly showed the stimulatory effect of Thymsol in vitro. In order to check how the phenomenon correlates with the production of IL-2, we added several concentrations of the extract ranging between $0.1-3.0 \mu \mathrm{g} \mathrm{mL}^{-1}$ to R73-stimulated splenocytes. Parallel cultures were treated with an IL2R $\alpha$ blocking $\mathrm{mAb}(\mathrm{OX}-39)$.

At first, we prepared three different samples of the same batch of Thymsol in order to study the variability of the results, obtained with the same preparation of splenocytes. Results given in Table 1 show that R73stimulated spleen lymphocytes produced a significantly higher level of IL-2 in Thymsol-treated cultures, compared to both control - untreated cultures and corresponding placebo-treated cultures. As expected, the production of IL-2 was significantly higher in the presence of OX-39 mAb. Comparable to the results from the proliferation assay, a slight stimulation of IL2-production (compared to the control-untreated cultures) was observed with certain concentrations of placebo.

The variability in the cytokine production between different samples of Thymsol was $12.0 \%$, as judged by the coefficient of variation (CV). The maximum stimulation (451 $\mathrm{pg} \mathrm{mL}^{-1}$ of IL-2) was obtained with sample 1 ( $2.0 \mu \mathrm{g} \mathrm{mL}^{-1}$ of Thymsol), normalized to the level of IL-2 in the corresponding culture of placebo. The minimum stimulation ( $366 \mathrm{pg} \mathrm{mL}^{-1}$ of IL-2) was 
Am. J. Immunol., 3 (2): 35-44, 2008

Table 1: Effect of different concentrations of three Thymsol samples and corresponding placebo samples on the production of IL-2 by the same population of rat splenocytes stimulated with anti-TCR antibody with or without a blocking anti-IL-2R $\alpha$ antibody (OX-39)

\begin{tabular}{|c|c|c|c|c|c|c|}
\hline & - OX-39 & + OX-39 & - OX-39 & + OX-39 & - OX-39 & + OX-39 \\
\hline Control & $149.3 \pm 24.5$ & $479.3 \pm 58.6$ & $149.3 \pm 24.5$ & $479.3 \pm 58.6$ & 0 & 0 \\
\hline \multicolumn{7}{|c|}{ Sample 1 of Thymsol/Placebo } \\
\hline Concent $\left(\mu \mathrm{g} \mathrm{mL}^{-1}\right)$ & \multicolumn{2}{|l|}{ Thymsol } & \multicolumn{2}{|l|}{ Placebo } & \multicolumn{2}{|c|}{ Thymsol-placebo differences } \\
\hline 0.1 & $159.0 \pm 36.1$ & $402.8 \pm 30.2$ & $217.4 \pm 40.2$ & $488.4 \pm 39.9$ & 58.4 & $-85.6 \bullet$ \\
\hline 0.5 & $221.3 \pm 16.2$ & $504.4 \pm 30.2$ & $201.0 \pm 21.3$ & $422.2 \pm 43.0$ & 20.3 & 82.2 \\
\hline 1.0 & $251.2 \pm 20.1 * * * \bullet$ & $620.0 \pm 41.2 * \bullet$ & $197.7 \pm 8.2^{*}$ & $501.3 \pm 28.0 *$ & 53.5 & 118.7 \\
\hline 1.5 & $296.1 \pm 23.2 * * * \bullet \bullet \bullet$ & $754.4 \pm 37.2 * * * \bullet \bullet \bullet$ & $182.2 \pm 20.6$ & $403.6 \pm 30.2$ & 113.9 & 350.8 \\
\hline 2.0 & $367.1 \pm 20.8 * * * \bullet \bullet \bullet$ & $864.4 \pm 50.1 * * * \bullet \bullet \bullet$ & $210.2 \pm 13.1^{*}$ & $413.4 \pm 50.0$ & 156.9 & 451.0 \\
\hline 2.5 & $208.5 \pm 12.8^{*}$ & $534.1 \pm 30.6 \bullet$ & $218.0 \pm 29.6^{*}$ & $452.4 \pm 20.0$ & -9.5 & 81.7 \\
\hline 3.0 & $196.3 \pm 20.8$ & $528.6 \pm 48.1 \bullet$ & $175.5 \pm 13.2$ & $377.6 \pm 40.8 *$ & 20.8 & 151.0 \\
\hline \multicolumn{7}{|c|}{ Sample 2 of Thymsol/Placebo } \\
\hline \multirow[t]{2}{*}{ Concent $\left(\mu \mathrm{g} \mathrm{mL}^{-1}\right)$} & \multicolumn{2}{|l|}{ Thymsol } & \multicolumn{2}{|l|}{ Placebo } & \multicolumn{2}{|c|}{ Thymsol-placebo differences } \\
\hline & - OX-39 & + OX-39 & - OX-39 & & - OX-39 & + OX-39 \\
\hline 0.1 & $148.1 \pm 20.6$ & $481.2 \pm 31.7$ & $138.6 \pm 17.3$ & $455.2 \pm 60.0$ & 95.0 & 26.0 \\
\hline 0.5 & $205.5 \pm 22.8^{*}$ & $601.3 \pm 34.4 * \bullet$ & $180.3 \pm 22.8$ & $475.3 \pm 50.1$ & 25.2 & 126.0 \\
\hline 1.0 & $214.4 \pm 13.9^{*} \bullet$ & $721.3 \pm 63.6^{* * \bullet \bullet \bullet}$ & $160.4 \pm 18.8$ & $355.3 \pm 40.8^{*}$ & 54.0 & 366.0 \\
\hline 1.5 & $231.2 \pm 30.6^{* \bullet \bullet}$ & $641.2 \pm 50.1 * \bullet \bullet \bullet$ & $139.1 \pm 10.8$ & $293.0 \pm 25.5^{* *}$ & 92.1 & 348.2 \\
\hline 2.0 & $230.6 \pm 18.7^{* *}$ & $540.6 \pm 30.9 \bullet \bullet \bullet$ & $188.2 \pm 20.6$ & $254.2 \pm 18.7 * * *$ & -23.6 & 286.4 \\
\hline 2.5 & $181.2 \pm 22.9$ & $508.4 \pm 70.1 \bullet$ & $171.3 \pm 11.6$ & $384.1 \pm 30.1$ & 9.9 & 124.3 \\
\hline 3.0 & $100.3 \pm 27.7$ & $468.3 \pm 29.4 \bullet \bullet$ & $123.4 \pm 14.2$ & $359.6 \pm 28.1^{*}$ & -23.1 & 108.7 \\
\hline \multicolumn{7}{|c|}{ Sample 3 of Thymsol/Placebo } \\
\hline \multirow[t]{2}{*}{ Concent. $\left(\mu \mathrm{g} \mathrm{mL}^{-1}\right)$} & \multicolumn{2}{|l|}{ Thymsol } & \multicolumn{2}{|l|}{ Placebo } & \multicolumn{2}{|c|}{ Thymsol-placebo differences } \\
\hline & - OX-39 & + OX-39 & - OX-39 & & - OX-39 & + OX-39 \\
\hline 0.1 & $121.3 \pm 10.2$ & $462.0 \pm 38.6$ & $136.4 \pm 14.6$ & $402.0 \pm 21.4$ & -15.1 & 60.0 \\
\hline 0.5 & $135.6 \pm 25.1$ & $688.3 \pm 52.3^{* * * \bullet}$ & $127.3 \pm 18.8$ & $543.1 \pm 39.6$ & 8.3 & 145.2 \\
\hline 1.0 & $241.3 \pm 61.4$ & $692.1 \pm 70.3^{*} \bullet$ & $150.2 \pm 26.1$ & $473.5 \pm 51.4$ & 91.1 & 218.6 \\
\hline 1.5 & $269.2 \pm 30.6^{* * * \bullet \bullet}$ & $864.0 \pm 101.3^{* * * * \bullet \bullet \bullet}$ & $149.8 \pm 15.2$ & $492.0 \pm 22.6$ & 119.3 & 372.0 \\
\hline 2.0 & $265.1 \pm 20.1 * * * \bullet \bullet \bullet$ & $694.3 \pm 38.8 * * \bullet \bullet \bullet$ & $183.1 \pm 9.2$ & $386.2 \pm 40.6$ & 82.0 & 308.1 \\
\hline 2.5 & $201.3 \pm 36.1$ & $511.3 \pm 60.8$ & $131.4 \pm 26.9$ & $416.3 \pm 31.4$ & 69.9 & 95.0 \\
\hline 3.0 & $141.3 \pm 10.1$ & $351.8 \pm 30.7 *$ & $125.2 \pm 22.4$ & $292.6 \pm 22.3$ & 16.1 & 59.2 \\
\hline
\end{tabular}

Splenocytes from one AO rat were cultivated for $48 \mathrm{~h}$ with three samples of Thymsol or placebo as described in Materials and methods. The levels of IL-2 in culture supernatants were detected by ELISA. Values are given as mean $\pm \mathrm{SD}(\mathrm{pg} / \mathrm{ml})$ of triplicates. $*=\mathrm{p}<0.05, * *=\mathrm{p}<0.01$, $* * *=p<0.005$ compared to corresponding cultures without Thymsol or placebo, $\bullet=p<0.05, \bullet=p<0.01, \bullet \bullet \bullet<<0.005$ compared to corresponding placebo cultures

calculated in the culture of sample $2\left(1.0 \mu \mathrm{g} \mathrm{mL}^{-1}\right.$ of Thymsol).

After these experiments, we compared the variability in the IL-2 production by three different samples of splenocytes (prepared from three separate spleens of AO rats), using the same sample of Thymsol and a control sample of placebo was tested in each experiment. Results presented in Table 2 show that the variability between different samples of target cells was higher $(\mathrm{CV}=20.1 \%)$. In this study maximal stimulation of IL-2 production was obtained with the sample 1 of splenocytes (548.0 $\mathrm{pg} \mathrm{mL}^{-1}, 1.5 \mu \mathrm{g} \mathrm{mL}^{-1}$ of Thymsol) whereas minimum stimulation of IL-2 production was measured in the culture of sample 2 of splenocytes (365.4 $\mathrm{pg} \mathrm{mL}^{-1}, 1.0 \mu \mathrm{g} \mathrm{mL}^{-1}$, of Thymsol).

In our previous work ${ }^{[18]}$ and (Vucevic et al., manuscript submitted) we presented pharmacological and immunological characteristics of a CTLE. The result relevant for this paper showed that except the lipids, as a dominant component, the extract contains about $0.3 \%$ bioactive peptides. CTLE extract stimulated the immune response in young and aged mice and rats and also improve wound healing. Although CTLE showed the immunomodulatory activity in vitro it was difficult to asses its effect properly due to difficulties in mixing the lipid component with water solution such as culture medium. This was the reason why we prepared a new formulation of the lipid extract, named Thymsol, using Cremophor EL as a lipid emulgator. Preliminary experiments demonstrated that this emulsion preparation was much better soluble in culture medium than the former CTLE. Therefore the main aim of this study was to check whether Thymsol retains its immunobiological effect in vivo and whether in vitro tests could be used for screening and standardization of this activity.

Based on our previous results (Vucevic et.al., manuscript submitted) which showed that a single dose 
Am. J. Immunol., 3 (2): 35-44, 2008

Table 2: Effect of different concentrations of Thymsol and corresponding placebo on the production of IL-2 by three different populations of rat splenocytes stimulated with anti-TCR antibody with or without a blocking anti-IL-2R $\alpha$ antibody (OX-39) Sample 1of splenocytes

\begin{tabular}{|c|c|c|c|c|c|c|}
\hline \multirow[t]{2}{*}{ Concent. $\left(\mu \mathrm{g} \mathrm{mL}^{-1}\right)$} & \multicolumn{2}{|l|}{ Thymsol } & \multicolumn{2}{|l|}{ Placebo } & \multicolumn{2}{|c|}{ Thymsol-placebo differences } \\
\hline & - OX-39+ OX-39 & - OX-39 & $+\mathrm{OX}-39$ & - OX-39 & + OX-39 & \\
\hline 0 & $201.0 \pm 16.4$ & $493.2 \pm 26.1$ & $201.0 \pm 16.4$ & $493.2 \pm 26.1$ & 0 & 0 \\
\hline 0.1 & $206.2 \pm 18.3$ & $481.6 \pm 24.2$ & $188.2 \pm 20.1$ & $424.3 \pm 36.2$ & 18.0 & 57.3 \\
\hline 0.5 & $321.4 \pm 28.1 * * * \bullet$ & $724.3 \pm 46.1 * * * \bullet \bullet \bullet$ & $243.0 \pm 25.1$ & $489.6 \pm 35.1$ & 78.4 & 234.7 \\
\hline 1.0 & $336.2 \pm 28.8^{* * * \bullet \bullet \bullet ~}$ & $717.3 \pm 51.1 * * * \bullet \bullet \bullet$ & $218.6 \pm 18.2$ & $508.4 \pm 33.6$ & 117.6 & 208.9 \\
\hline 1.5 & $492.4 \pm 33.1 * * * \bullet \bullet \bullet$ & $1065.2 \pm 48.2 * * * \bullet \bullet \bullet$ & $233.9 \pm 30.1$ & $517.2 \pm 40.0$ & 258.5 & 548.0 \\
\hline 2.0 & $488.2 \pm 32.8^{* * * * \bullet \bullet}$ & $803.1 \pm 55.2 * * * \bullet$ & $246.2 \pm 37.7$ & $601.2 \pm 59.3 *$ & 242.0 & 201.9 \\
\hline 2.5 & $402.6 \pm 30.2 * * * \bullet \bullet \bullet$ & $950.2 \pm 59.9 * * * \bullet \bullet \bullet$ & $250.2 \pm 18.7 *$ & $561.3 \pm 42.2$ & 152.4 & 388.9 \\
\hline 3.0 & $301.0 \pm 50.2^{*}$ & $591.3 \pm 60.8^{*}$ & $235.0 \pm 30.6$ & $488.1 \pm 20.0$ & 66.0 & 103.2 \\
\hline \multicolumn{7}{|c|}{ Sample 2 of splenocytes } \\
\hline \multirow[t]{2}{*}{ Concent. $\left(\mu \mathrm{g} \mathrm{mL}^{-1}\right)$} & \multicolumn{2}{|l|}{ Thymsol } & \multicolumn{2}{|l|}{ Placebo } & \multicolumn{2}{|c|}{ Thymsol-placebo differences } \\
\hline & - OX-39+ OX-39 & - OX-39 & & - OX-39 & $+\mathrm{OX}-39$ & \\
\hline 0 & $168.3 \pm 10.2$ & $399.4 \pm 25.1$ & $168.3 \pm 10.2$ & $399.4 \pm 25.1$ & 0 & 0 \\
\hline 0.1 & $175.1 \pm 12.3$ & $406.3 \pm 22.0$ & $170.1 \pm 11.3$ & $388.2 \pm 20.1$ & 5.0 & 18.1 \\
\hline 0.5 & $198.3 \pm 26.8$ & $430.0 \pm 31.1$ & $182.2 \pm 11.0$ & $408.2 \pm 25.2$ & 16.1 & 21.8 \\
\hline 1.0 & $291.3 \pm 20.8 * * *$ & $803.4 \pm 36.6$ *** ••• & $231.1 \pm 30.2^{* *}$ & $438.0 \pm 30.6$ & 60.2 & 365.4 \\
\hline 1.5 & $267.0 \pm 31.4 * *$ & $724.3 \pm 40.1 * * * \bullet \bullet \bullet$ & $217.2 \pm 18.0^{*}$ & $456.2 \pm 26.0$ & 49.8 & 268.1 \\
\hline 2.0 & $181.4 \pm 9.8$ & $504.2 \pm 30.1 * * \bullet$ & $201.3 \pm 18.2$ & $433.2 \pm 12.8$ & -19.9 & 71.0 \\
\hline 2.5 & $198.3 \pm 10.2^{*}$ & $528.4 \pm 16.2 * * * \bullet \bullet \bullet$ & $179.3 \pm 12.0$ & $359.6 \pm 22.6$ & 19.0 & 168.8 \\
\hline 3.0 & $150.2 \pm 8.8$ & $388.3 \pm 18.9$ & $164.0 \pm 12.2$ & $401.2 \pm 12.8$ & -13.8 & -12.9 \\
\hline \multicolumn{7}{|c|}{ Sample 3 of splenocytes } \\
\hline \multirow[t]{2}{*}{ Concent. $\left(\mu \mathrm{g} \mathrm{mL}^{-1}\right)$} & \multicolumn{2}{|l|}{ Thymsol } & \multicolumn{2}{|l|}{ Placebo } & \multicolumn{2}{|c|}{ Thymsol-placebo differences } \\
\hline & - OX-39+ OX-39 & - OX-39 & & - OX-39 & $+\mathrm{OX}-39$ & \\
\hline 0 & $180.2 \pm 20.8$ & $478.4 \pm 36.2$ & $180.2 \pm 20.8$ & $478.4 \pm 36.2$ & 0 & 0 \\
\hline 0.1 & $159.0 \pm 36.1 \bullet$ & $402.8 \pm 30.2 \bullet$ & $217.4 \pm 40.2$ & $488.4 \pm 39.9$ & 58.4 & -85.6 \\
\hline 0.5 & $221.3 \pm 16.2$ & $504.4 \pm 30.2 \bullet \bullet$ & $201.0 \pm 21.3$ & $422.2 \pm 43.0$ & 20.3 & 82.2 \\
\hline 1.0 & $251.2 \pm 20.1 * \bullet$ & $620.0 \pm 41.2^{* * \bullet}$ & $197.7 \pm 8.2$ & $501.3 \pm 28.0$ & 53.5 & 118.7 \\
\hline 1.5 & $296.1 \pm 23.2 * * * \bullet \bullet \bullet$ & $754.4 \pm 37.2 * * * \bullet \bullet$ & $182.2 \pm 20.6$ & $403.6 \pm 30.2 *$ & 113.9 & 350.8 \\
\hline 2.0 & $367.1 \pm 20.8 * * * \bullet \bullet \bullet$ & $864.4 \pm 50.1 * * * \bullet \bullet \bullet$ & $210.2 \pm 13.1$ & $413.4 \pm 50.0$ & 156.9 & 451.0 \\
\hline 2.5 & $208.5 \pm 12.8$ & $534.1 \pm 30.6 \bullet$ & $218.0 \pm 29.6$ & $452.4 \pm 20.0$ & -9.5 & 81.7 \\
\hline 3.0 & $196.3 \pm 20.8$ & $528.6 \pm 48.1 \bullet$ & $175.5 \pm 13.2$ & $377.6 \pm 40.8^{*}$ & 20.8 & 151.0 \\
\hline
\end{tabular}

Splenocytes from three AO rats were cultivated separately with the same sample of Thymsol or placebo, for the same sample of Thymsol or placebo $48 \mathrm{~h}$ as described in Materials and methods. The levels of IL-2 in culture supernatants were detected by ELISA. Values are given as mean $\pm \mathrm{SD}\left(\mathrm{pg} \mathrm{mL}^{-1}\right)$ of triplicates. $*=\mathrm{p}<0.05, * *=\mathrm{p}<0.01, * * *=\mathrm{p}<0.005$ compared to corresponding cultures without Thymsol or placebo, $\bullet=$ $\mathrm{p}<0.05, \bullet \bullet \mathrm{p}<0.01, \bullet \bullet \bullet \mathrm{p}<0.005$ compared to corresponding placebo cultures

(5 mg/rat) of CTLE enhanced an allogeneic immune response in vivo, in this work we used the same dose of Thymsol in a model of KLH antigen-specific immune response, but the dose was divided into two parts ( 2.5 $\mathrm{mg}$ at the time of immunization and the second half of dose four days later).The results showed that Thymsol stimulated the immune response, as documented by higher cellularity of regional lymph nodes, higher proliferative response of lymph node lymhocytes following their restimulation with KLH in vitro and subsequent increased production of IL-2. These results are generally in agreement with already published results with other different preparations of thymus extracts or thymic peptides isolated from these extracts $^{[8,10]}$. However, the extent of the stimulatory activity varied depending on investigated species, type of thymic preparation, its dose and the type of immunization protocol. Since the content of peptides in Thymsol is low, our working hypothesis, to be tested in next experiments, is that lipid components, especially gangliosides, act synergistically with peptides in stimulating the immune response and that lipids predominantly stimulate antigen-presenting cells (APC). It has been shown that thymic peptides are also responsible for stimulation of the components of the innate immune system. Tzehoval et al., ${ }^{[20]}$ demonstrated that thymosin $\alpha 1$ and $\beta 4$ potentiate the antigen-presenting functions of macrophages. Macrophages pretreated with thymosin $\alpha 1$ significantly enhanced the production of proinflammatory cytokines and this finding correlated with upregulated expression of Toll-like receptors and nucleotide-binding 
oligomerization domain (Nod)2 protein $^{[21]}$. Thymosin $\alpha 1$ also induces the functional maturation and IL-12 production by dendritic cells through the p38 mitogen activated protein kinase/NF- $\kappa$ B pathway ${ }^{[22]}$.

The main result from this study was showed that Thymsol exerted bimodal influence on splenocyte proliferation: stimulation of lower concentrations and inhibition at higher concentrations. Both phenomena were relatively stable in four independent experiments, conducted within two months, but the increase in the proliferative activity and the maximal stimulatory dose varied between experiments. Better stimulatory activity was seen when an anti-TCR mAb was used for cell stimulation, compared to ConA. Under both experimental conditions the response of proliferating $\mathrm{T}$ cells within total splenocytes depends on APC and Thymsol was ineffective on purified $\mathrm{T}$ cells (data not shown). A slight stimulation of lymphocyte proliferation was observed with some dilutions of placebo and our preliminary results suggest that this effect was caused by Cremophor EL.

The proliferation (clonal expansion) of $\mathrm{T}$ cells in vitro and in vivo is a consequence of produced IL-2 which binds to IL-2R expressed on $\mathrm{T}$ cells upon activation $^{[23]}$. Therefore it was logic to study whether in our in vitro system an increase in $\mathrm{T}$-cell proliferation was accompanied by increased IL-2 production. We confirmed this relationship and showed that, generally, the level of IL-2 in culture supernatants correlated with the extent of cellular proliferation. However, the differences in the levels of IL-2 between Thymsoltreated cultures and corresponding controls were more pronounced when a locking anti-IL-2R mAb was added.

Up to now, a large number of publications demonstrated that an increase in IL-2 production is one of the main biological effects of thymus extracts or synthetic thymic peptides, but our work is the first report showing the same activity of a lipid thymus extract. Lin and Low ${ }^{[24]}$ used three different thymic extracts (one bovine and two porcine thymus extracts) and showed that all three preparations at the concentrations ranging between 12.5 and $50 \mu \mathrm{g} \mathrm{mL}^{-1}$ increased lymphocyte proliferation as well as production of IL-2, interferon- $\gamma$ (IFN- $\gamma$ ) and tumor necrosis factor- $\alpha$ (TNF- $\alpha)$ in vitro by human cord blood lymphocytes. The differences in stimulatory potential between the extracts were evident, suggesting that the different immunostimulating effects may reflect not only the species differences but also the difference in preparation procedures. This finding also suggests that different components in these thymic

Extracts may be responsible for different biological activity. Zatz and Goldstein ${ }^{[25]}$ found that thymosin fraction 5, containing one or more biologically active components, caused a two-to threefold enhancement of the proliferative response and production of IL-2 when murine thymocytes were cultured with alloantigen stimulator cells. In addition, the production of colony stimulatory factor (CSF) was increased up to seven fold. Similarly, thymic humoral factor (THF) promoted IL-2 production in intact and thymus-deprived mice both in vitro and in vivo ${ }^{[26]}$.

THF-gamma 2, a synthetic octapeptide, increased production of IL-2 by lymphocytes from human cord blood $^{[12]}$. Goso et al., ${ }^{[27]}$ also reported that a few nanograms of THF-gamma 2 , injected in ageing mice in vivo raised the frequency of mitogen-responsive $\mathrm{T}$ cells in the thymus and spleen and restore IL-2 production by mitogen-stimulated spleen cells. The effect was 400fold efficient in stimulation of the cell activity than thymosin $\alpha 1$.

Cordero et al. ${ }^{[11]}$ demonstrated that prothymosin a1 enhanced IL-2R expression by normal human $\mathrm{T}$ cells. This enhancement was dose dependent and paralleled by increased proliferative response to PHA. Prothymosin $\alpha 1$ increased the anti-CD3 activated killer cytotoxicity of human peripheral blood mononuclear cells (PBMNC) from healthy donors, the expression of adhesion molecules and IL-2R, and production of IL-2 and IL-1 $\beta$. In addition this biological response modifier induced autologous tumor-reactive $\mathrm{CD}^{+}$and $\mathrm{CD} 56^{+}$ lymphocytes with cytotoxic activity, suggesting its significance as an alternative protocol aimed to improve the clinical results in cellular adoptive immunotherapy of cancer ${ }^{[28]}$. In line of these findings are the results of Bepler ${ }^{[29]}$ who showed that thymosin $\alpha 1$, derived from prothymosin $\alpha 1$, restores normal T-cell functions by increasing IL-2 production and expression of IL-2R in normal mitogen-stimulated $\mathrm{T}$ cells both in human and mice.

It seems that thymic preparations modify the Th1/Th2 balance such they stimulate Th1 and inhibit Th2 immune response. This hypothesis was confirmed by Cillari et al. ${ }^{[30]}$ who showed that thymopentin (TP) increased the production of Th1 cytokines (IL-2, TNF- $\alpha$ and IFN- $\gamma$ ) and down-regulated the production of Th2 cytokines such as IL-3, IL-4 and IL-5. TP was also efficient in vivo in mice with experimental gut-derived sepsis. The significantly reduced mortality of the animals was followed by reduced production of IL-4 
and increased production of IL-2 ${ }^{[17]}$.Similarly, thymosin $\alpha 1$ treatment induced a significant increase in production of IL-2 and a decrease in production of IL-4 and IL-10 by $\mathrm{T}$ cells from patients with chronic hepatitis $\mathrm{C}^{[31]}$.

Our results showed that higher concentrations of Thymsol inhibited proliferation of spleen $\mathrm{T}$ cells in a dose dependent manner. A part of the observed effect was probably a consequence of the components of solvent. Although the mechanisms at the immunosuppressive effect of this extract were not investigated, we believe that lipid components are responsible for the most of the suppressive activity. However, there were some publications about the suppressive activity of peptide fractions. The inhibitory effect of thymosin fraction 5 on IL-2 production by PBMNC was found in some patients with active rheumatoid arthritis ${ }^{[32]}$. In addition, the study from the same laboratory also confirmed that thymosin fraction 5 inhibited the proliferation of human PBMNC as well as IL-2 production in the presence of suboptimal concentrations of $\mathrm{PHA}^{[33]}$. Similarly, Grinblat et al., ${ }^{[34]}$ showed that THF inhibited T-cell proliferation if added after ConA stimulation.

An important question resulting from this work and similar studies is related to the choice of the assay for evaluation of the immunobiological activity of thymic preparations. According to our results, we believe that lymphocyte proliferation assay, based on $\left[{ }^{3} \mathrm{H}\right]-$ thymidine incorporation and IL-2 production assay could be standardized for these purposes. The limitation factor in using the proliferation assay is considerable inter-assay variability and needs for radioactive materials. Our attempts to replace the $\left[{ }^{3} \mathrm{H}\right]$-thymidine method with an alternative assay, such as MTT test, was unsuccessful due to lower sensitivity of MTT. Based on our previous experience with thymic extracts and other biological modifiers ${ }^{[35]}$, including the results presented in this work, we concluded that the level of produced IL-2 could be the most reliable parameter for testing the immunobiological activity of thymus extracts. Our results also suggest that the extent of stimulation in IL-2 production is more pronounced if IL-2R $\alpha$ are blocked, and because of that utilization of the secreted IL-2 is prevented. Using such an approach with splenocyte cultures stimulated with an anti-TCR $\mathrm{mAb}$, we showed that variability between three samples of the same batch of Thymsol tested on the same population of target cells was about $12 \%$. This $\mathrm{CV}$ is very acceptable for biological tests. As expected the variability in the production of IL-2 between different samples of target cells, treated with the same sample of the extract was higher (about 20\%). Higher variability in the assay could be explained by different immunological status of the individual animals. The difference in the in vitro lymphocyte response to mitogens and other stimuli strongly depends on the activation properties of accessory cells (DC and macrophages) present in the total population of splenocytes $^{[36]}$. This variability is especially seen in older rats (data not shown) which were used in this study. However, as mentioned before, older animals are more convenient for screening the immunobiological activity of thymus preparations than young animals ${ }^{[4,7]}$. The use of some permanent T-cell lines will be an alternative for screening assay instead of total lymphocytes. Unfortunately, Thymsol is not efficient in triggering $\mathrm{T}$-cell activation and IL-2 production without accessory cells.

In conclusion, according to the obtained results we propose a method for quantification of the immunobiological activity of Thymsol. The method is based on the stimulation of IL-2 production by rat splenocytes in culture stimulated with an anti-TCR $\mathrm{mAb}$ in the presence of a blocking anti-IL-2R mAb. We suggest that several stimulatory concentrations of the extract (at least three different samples) should be tested on the same population of target cells (total splenocytes). The highest mean concentration of produced IL-2 subtracted from the highest mean concentration of IL-2 in culture with placebo could be the quantitative indicator of its immunobiological effect. We also suggest that one $\mathrm{pg} \mathrm{mL}^{-1}$ of such calculated value of IL-2 corresponds to one unit (U) of the biological activity of Thymsol. It remains to be tested in future studies whether this parameter is stable and reliable marker for assessing the biological activity, not only different batches of Thymsol, but also similar thymus extracts.

\section{ACKNOWLEDGEMENTS}

This work was partly supported by the Ministry of Science and Environmental Protection of Republic of Serbia (grant P006927) and by Serbian Academy of Sciences and Arts. The authors thank S. Gasic, S. Vasilijic and I. Majstorovic for technical assistance.

\section{REFERENCES}

1. Gemain, R.N. 2002. T-cell development and the CD4-CD8 lineage decesion. Nat. Rev. Immunol., 2(5):309-322.

2. Dardenne, M. and W. Savino, 1994. Control of thymus physiology by peptidic hormones and neuropeptides. Immunol. Today, 15 (11): 518-523. 
3. Weksler, M.E. and G.W. Siskind, 1984. The cellular basis of immune senescence. Monogr. Dev. Biol., 17:110-121.

4. Frasca, D., L. Adorini, C. Mancini and G. Doria, 1986. Reconstitution of $\mathrm{T}$ cell functions in aging mice by thymosin alpha 1 . Immunopharmacology, 11(3):155-163.

5. Doria, G., L. Adorini and D. Frasca, 1986. Immunoregulation of antibody responses in aging mice, In ,Aging and the Immune Response (E. Goidl, Ed.). pp. 143-176, Dekker, New York.

6. Meroni, P.L., W. Barcellini, D. Frasca, C. Sguotti, M.O. Borghi, G. De Bartolo, G. Doria and C. Zanussi, 1987. In vivo immunopotentiating activity of thymopentin in aging humans: increase of IL-2 production. Clin. Immunol. Immunopathol., 42(2): 151-159.

Zatz, M.M. and A.L. Goldstein, 1985. Thymosins, lymphokines, and the immunology of aging. Gerontology, 31(4): 263-277.

8. Garaci, E., F. Pica, G. Rasi and C. Favalli, 2000. Thymosin alpha 1 in the treatment of cancer: from basic research to clinical application. Int. $\mathrm{J}$. Immunopharmacol., 22(12): 1067-1076.

9. Cordero, O.J., A. Pineiro and M. Nogueira, 1999. Thymic peptides and preparations: an update. Arch. Immunol. Ther. Exp. Warsz., 47:77-82.

10. Kouttab, N.M., M. Prada and P. Cazzola, 1989. Thymomodulin: biological properties and clinical applications. Med. Oncol. Tumor Pharmacother., 44(2):159-164.

11. Cordero, O.J., C.S. Sarandeses, J.L. Lopez, E. Cancio, B.J. Regueiro and M. Nogueira, 1991. Prothymosin alpha enhances interleukin 2 receptor expression in normal human T-lymphocytes. Int. J. Immunopharamcol., 13(8): 1059-1065.

12. Ben-Hur, H., M. Pecht, L. Netzer, R. Borenstein, I. Blickstein, Y. Burstein and N. Trainin, 1990. Immune modulation exerted by thymic humoral factor (THF-gamma 2), on T-cell subsets and IL-2 production of umbilical cord blood lymphocytes. Immunopharmacol. Immunotoxical., 12(1): 123-133.

13. Kouttab, N.M., A.L. Goldstein, M. Lu, L. Lu, B. Campbell and A.L. Maizel, 1988. Production of human $\mathrm{B}$ and $\mathrm{T}$ cell growth factor in enhanced by thymic hormones. Immunopharmacology, 16(2): 97-105.
14. Barcellini, W., P.L. Meroni, M.O. Borghi, D. Frasca, R. Perego, G. Doria and C. Zanussi, 1988. In vivo immunopotentiating activity of thymopentin in aging humans: modulation of IL-2 receptor expression. Clin. Immunol. Immunopathol., 48(2): 140-149.

15. Baxevanis, C.N., S. Frillingos, K. Seferiadis, G.J. Reclos, P. Arsenis, A. Katsiyiannis, E. Anastasopoulos, O. Tsolas and M. Papamichail, 1990. Enhancement of human T lymphocytes function by prothymosin alpha: increased production of interleukin-2 and expression of interleukin-2 receptors in normal human peripheral blood $\mathrm{T}$ lymphocytes. Immunopharmacol. Immunotoxical., 12(4):595-617.

16. Sztein, M.B. and S.A. Serrate, 1989. Characterization of the immunoregulatory properties of thymosin alpha 1 on interleukin-2 production and interleukin- 2 receptor expression in normal human lymphocytes. Int. J. Immunopharmacol., 11(7): 789-800.

17. Braga, M., L. Gianotti, O. Gentilini, C. Fortis, G. Consogno and V. Di Carlo, 1996. Thymopentin modulates Th1 and Th2 cytokine response and host survival in experimental injury. J. Surg. Res., 62(2): 197-200.

18. Radeta, M., J. Novakovic, M. Vico-Stevanovic, S. Simic and A. Pirožkov, 2007. Isolation of thymus gland fractions and determination of their biological activity. J. Serb. Chem. Soc., 72: 225-234.

19. Rowe, R.C., P.J. Sheskey and P.J. 2001. Weller, Pharmaceutical Excipients, American Association, Washington, DC, USA and Pharmaceutical Press, London, UK.

20. Tzehoval, E., M.B. Sztein and A.L. Goldstein, 1989. Thymosins alpha 1 and beta 4 potentiate the antigen-presenting capacitiy of macrophages. Immunopharmacology, 18(2): 107-113.

21. Tarang, S. and A. Sodhi, 2007. Expression of Tolllike Receptors (TLRs) and Nucleotide-binding Oligomerization Domain (NODs) in murine peritoneal macrophages on in vitro treatment with Thymosin $\alpha$ 1. Am. J. Immunol., 3(1): 15-24.

22. Romani, L., R. Bistoni, S. Gaziano, C. Bozza, K. Montagnoli, L. Perruccio, S. Pitzurra, A. Bellocchio, G. Velardi, P. Rasi, di Franceso and E. Garaci, 2004. Thymosin $\alpha 1$ activates dendritic cells for antifungal Th1 resistance through toll-like receptor signaling. Blood, 103(11): 4232-4239.

23. Benczik, M. and S.L. Gaffen, 2004. The interleukin (IL)-2 family cytokines: survival and proliferation signaling pathways in $\mathrm{T}$ lymphocytes. Immunol. Invest., 33(2): 109-42. 
24. Lin, C.Y. and T.L. Low, 1989. A comparative study on the immunological effects of bovine and porcine thymic extracts: Induction of lymphoproliferative response and enhancement of interleukin-2, gamma-interferon and tumor necrotic factor production in vitro on cord blood lymphocytes. Immunopharamcology, 18(1): 1-10.

25. Zatz, M.M. and A.L. Goldstein, 1985. Mechanism of action of thymosin.l. Thymosin fraction 5 increases lymphokine production by mature murine $\mathrm{T}$ cells responding in a mixed lymphocyte reaction. J. Immunol., 134(2): 1032-1038.

26. Umiel, T., M. Pecht and N. Trainin, 1984. THF, a thymic hormone, promotes interleukin-2 production in intact and thymus deprived mice. J. Biol. Rsponse Mod., 3(4): 423-434.

27. Goso, C., D. Frasca and G. Doria, 1992. Effect of synthetic thymic humoral factor (THF-gamma 2) on $\mathrm{T}$ cell activities in immunodeficient ageing mice. Clin. Exp. Immunol., 87(3):346-351.

28. Baxevanis, C.N., G. Spanakos, I.F. Voutsas, A.D. Gritzapis, O.E. Tsitsilonis, A. Mamalaki and M. Papamichail, 1999. Increased generation of autologous tumor-reactive lymphocytes by antiCD3 monoclonal antibody and prothymosin alpha. Cancer Immunol. Immunother., 48(2-3): 71-84.

29. Bepler, G. 1994. Thymosin alpha-1 as adjunct for conventional therapy of malignant tumors: a review. Cancer Invest., 12(5):491-496.

30. Cillari, E., S. Milano, R. Perego, G. Gromo, R. D'Agostino, F. Arcoleo and M. Dieli, 1992. Modulation of IL-2, IFN-gamma, TNF-alpha and IL-4 production in mice of different ages by thymopentin. Int. J. Immunopharmacol., 14(6): 1029-1035.
31. Andreone, P., C. Cursaro, A. Gramenzi, M. Margotti, E. Ferri, S. Talarico, M. Biselli, F. Felline, Tuthill, artins, E., Gasbarrini, G. and M. Bernardi, 2001. In vitro effect of thymosinalpha1 and interferon-alpha on Th1 and Th2 cytokine synthesis in patients with chronic hepatitis C. J. Viral. Hepat., 8(3):194-201.

32. Wolf, R. E. and V.C. Hall, 1987. Interleukin-2 production and effect of thymosin fraction 5 on interleukin-2 production in rheumatoid arthritis. J. Rheumatol., 14(5):898-901.

33. Wolf, R. E. and R.D. Maca, 1986. Suppressive effect of thymosin fraction 5 on proliferation of cultured human $\mathrm{T}$ lymphocytes. Immunopharmacology, 12(3):233-240.

34. Grinblat, J., Schauenstein, K., Saltz, E., Trainin, N. and A. Globerson, 1983. Regulatory effect of thymus humoral factor on $\mathrm{T}$ cell growth factor in aging mice. Mech. Ageing. Dev., 22(3-4):209-218.

35. Colic, M., Vucevic, D., Kilibarda, V., Radicevic, N. and M. Savic, 2002. Modulatory effect of garlic extracts on proliferation of T-lymphocytes in vitro stimulated with concanavalin A. Phytomedicine, 9:117-124. 